\title{
So Many Diagnostic Tests, So Little Time: Review and Preview of Candida auris Testing in Clinical and Public Health Laboratories
}

\author{
Emily K. Dennis ${ }^{1}$, Sudha Chaturvedi ${ }^{1,2}$ and Vishnu Chaturvedi ${ }^{1 *}$ \\ ${ }^{1}$ Mycology Laboratory, Wadsworth Center, New York State Department of Health, Albany, NY, United States, ${ }^{2}$ Department \\ of Biomedical Sciences, University at Albany, Albany, NY, United States
}

\section{OPEN ACCESS}

Edited by:

Neeraj Chauhan,

Rutgers Biomedical and Health

Sciences, United States

Reviewed by:

Amir Arastehfar,

Westerdijk Fungal Biodiversity

Institute, Netherlands Javier Pemán,

University and Polytechnic Hospital of La Fe, Spain

*Correspondence:

Vishnu Chaturvedi

vishnu.chaturvedi@health.ny.gov

Specialty section:

This article was submitted to Infectious Agents and Disease,

a section of the journal

Frontiers in Microbiology

Received: 12 August 2021 Accepted: 13 September 2021

Published: 07 October 2021

Citation:

Dennis EK, Chaturvedi S and Chaturvedi V (2021) So Many

Diagnostic Tests, So Little Time: Review and Preview of Candida auris Testing in Clinical and Public Health

Laboratories.

Front. Microbiol. 12:757835 doi: 10.3389/fmicb.2021.757835
The recognition of a new yeast, Candida auris, in 2009 in East Asia, and its rapid global spread, was a reminder of the threats posed by multidrug-resistant fungal pathogens. C. auris had likely remained unrecognized for a long time as accurate tests were not available. The laboratory community responded to the $C$. auris challenge by publishing 35 new or revised diagnostic methods between 2014 and early 2021. The commercial sector also modified existing diagnostic devices. These $C$. auris diagnostic tests run the gamut from traditional culture-based differential and selective media, biochemical assimilations, and rapid protein profiles, as well as culture-independent DNA-based diagnostics. We provide an overview of these developments, especially the tests with validation data that were subsequently adopted for common use. We share a workflow developed in our laboratory to process over 37,000 C. auris surveillance samples and 5,000 C. auris isolates from the outbreak in the New York metropolitan area. Our preview covers new devices and diagnostic approaches on the horizon based on microfluidics, optics, and nanotechnology. Frontline laboratories need rapid, cheap, stable, and easy-to-implement tests to improve $C$. auris diagnosis, surveillance, patient isolation, admission screening, and environmental control. Among the urgent needs is a lateral flow assay or similar device for presumptive $C$. auris identification. All laboratories will benefit from devices that allow rapid antifungal susceptibility testing, including detection of mutations conferring drug resistance. Hopefully, multiplex test panels are on the horizon for synergy of $C$. auris testing with ongoing surveillance of other healthcare-associated infections. C. auris genome analysis has a proven role for outbreak investigations, and diagnostic laboratories need quick access to regional and national genome analysis networks.

Keywords: PCR, real-time PCR, MALDI-TOF MS, biosensor, laboratory-developed tests, clinical, surveillance, healthcare-associated infections 


\section{Candida auris, A NOVEL PATHOGEN}

Clinical laboratories made significant progress in the identification of fungal pathogens with the introduction of ribosomal RNA gene sequencing and matrix-assisted laser desorption ionization-time of flight mass spectrometry (MALDITOF MS) (White et al., 1990; Qian et al., 2008; Marklein et al., 2009). These DNA- and protein-based approaches enhanced the capacity of many frontline laboratories to recognize new pathogens, which were previously the province of highly specialized centers of excellence (Sullivan et al., 1995; AlcobaFlorez et al., 2005; Sugita et al., 2006; Jensen and Arendrup, 2011; Cendejas-Bueno et al., 2012; Castanheira et al., 2013; Eddouzi et al., 2013; Tsang et al., 2014). This scenario played out perfectly when Candida auris was recognized as a new yeast species by Satoh et al. (2009). The authors studied a single yeast isolate from the external ear canal discharge of an elderly patient at a Tokyo metropolitan hospital using biochemical tests and ribosomal RNA gene sequences (ITS and D1-D2) to delineate novel C. auris formally (Satoh et al., 2009). Around the same timeframe, Kim et al. (2009) reported 15 isolates of a novel Candida species, now confirmed as C. auris, from ear canals of chronic otitis media patients in South Korea. These isolates were susceptible to relatively high concentrations of amphotericin B and fluconazole. A subsequent study from South Korea by Lee et al. (2011) established C. auris as a causal agent of fatal fungemia with intrinsic and acquired resistance to fluconazole. The two teams highlighted misidentification of $C$. auris by commercial systems. They also emphasized the value of internal transcribed spacer (ITS) sequencing as a confirmatory test (Kim et al., 2009; Lee et al., 2011). Teun Boekhout's group reclassified Candida haemulonii species complex to recognize C. haemulonii, $C$. haemulonii var. vulnera, Candida pseudohaemulonii, Candida duobushaemulonii, and C. auris (Cendejas-Bueno et al., 2012). Notably, these investigators reported that MALDI-TOF MS was as good as the ITS sequencing for identification purposes (Cendejas-Bueno et al., 2012). Thus, within a short span of 4 years, a rare group of yeast species with intrinsic antifungal resistance was characterized for clinical significance, and the MALDI-TOF MS test was prescribed for rapid laboratory identification.

\section{Candida auris INTERNAL TRANSCRIBED SPACER (ITS) AND MATRIX-ASSISTED LASER DESORPTION IONIZATION-TIME OF FLIGHT MASS SPECTROMETRY}

Subsequent notable developments in the C. auris saga involved reports from outside East Asia. Sarma et al. (2013) described two C. auris isolates from candidemia cases from a hospital in North India. These isolates were amphotericin B- and fluconazoleresistant. The tally was most likely higher than reported, as only two of 15 isolates tentatively identified as C. haemulonii using a commercial yeast kit were sent out for re-identification by ITS sequencing (Sarma et al., 2013). Later, Chowdhury and coworkers described a series of $C$. auris cases from North and South India (Chowdhary et al., 2013, 2014). The authors suggested a clonal population based on amplicon typing and noted nucleotide variability in ITS gene sequences from East Asian C. auris isolates (Chowdhary et al., 2013, 2014). The C. auris isolates in these series were resistant to fluconazole, voriconazole, caspofungin, and flucytosine (Chowdhary et al., 2014). An additional case of fluconazole-resistant $C$. auris candidemia was reported from Kuwait in 2014, attesting to broader distribution in South Asia and Middle East (Emara et al., 2015). Also, in 2014, four cases of fluconazole-resistant $C$. auris candidemia were described from South Africa, and the investigators reported nucleotide variability in ITS sequences (Magobo et al., 2014). Thus, multiple reports documented widespread misidentification of $C$. auris by available specialized culture media, biochemical test kits, or commercial systems, highlighting the need for ITS sequencing (Chowdhary et al., 2013, 2014; Sarma et al., 2013; Magobo et al., 2014; Won et al., 2014; Emara et al., 2015). Using a more extensive collection of 102 C. auris isolates, the Chowdhury group also affirmed an earlier report by Cendejas-Bueno et al. (2012) on the suitability of MALDI-TOF MS as a more facile approach for C. auris confirmation (Kathuria et al., 2015; Prakash et al., 2016). In a preliminary study, VITEK MS instrument was found to be efficient in identification of eight of twelve reference strains of C. auris (Girard et al., 2016). Ghosh et al. (2015) and Bao et al. (2018) created main spectrum projections (MSP) and an in-house database (CMdb), respectively, to demonstrate it was possible to identify $C$. auris using a commercial Bruker Biotyper MALDI-TOF MS system. Other investigators also generated in-house databases to improve their Bruker MALDITOF MS reference library (Ceballos-Garzon et al., 2020). Of note, the US Food and Drug Administration (FDA) approved the BRUKER MALDI Biotyper CA system (April 20, 2018) and the bioMérieux Vitek MS (December 21, 2018) for C. auris identification (Zhu et al., 2020).

\section{Candida auris PCR AND LOOP-MEDIATED ISOTHERMAL AMPLIFICATION}

Polymerase chain reaction (PCR) in many configurations remains the technology of choice for newly described laboratory tests for C. auris (Table 1). Among the most straightforward applications, a duplex one-tube ITS-PCR assay was developed to speciate C. auris from C. haemulonii by the size selection of amplicons (Theill et al., 2018). Another direct PCR application targeted glycosylphosphatidylinositol (GPI) protein-encoding genes to speciate $C$. auris and 18 other Candida species by gel visualization of different size amplicons (Ruiz-Gaitan et al., 2018). The Boekhout group described novel tetraplex PCR and 21Multiplex PCR for C. auris and other closely related and other yeast species, and extensive testing with 405 reference strains and 804 clinical strains of yeasts from three different countries (Arastehfar et al., 2018, 2019a,b,c). Prospective and retrospective validations were performed in hospitals that appear not to have C. auris (Arastehfar et al., 2018, 2019a). Although targeted for 
TABLE 1 | Candida auris culture-independent DNA-based identification and confirmation methods.

\begin{tabular}{|c|c|c|c|c|c|c|c|c|c|}
\hline Method & Target & $\begin{array}{l}\text { C. auris (No. } \\
\text { isolates) }\end{array}$ & $\begin{array}{l}\text { Closely-Related } \\
\text { Yeasts (No. isolates) }\end{array}$ & $\begin{array}{l}\text { Other Fungi (No. } \\
\text { isolates) }\end{array}$ & $\begin{array}{l}\text { Clinical specimen } \\
\text { (No.) }\end{array}$ & $\begin{array}{l}\text { Sensitivity } \\
(\%)\end{array}$ & $\begin{array}{l}\text { Specificity } \\
(\%)\end{array}$ & $\begin{array}{c}\text { LOD } \\
\text { (CFU/reaction) }\end{array}$ & References \\
\hline \multicolumn{10}{|l|}{ PCR } \\
\hline & GPI & 139 & 18 & ND (Not Done) & ND & 98 & 100 & ND & $\begin{array}{l}\text { Ruiz-Gaitan } \\
\text { et al., } 2018\end{array}$ \\
\hline & ITS2 & 20 & 30 & ND & ND & 100 & 100 & ND & $\begin{array}{l}\text { Theill et al., } \\
2018\end{array}$ \\
\hline \multicolumn{10}{|c|}{ Multiplex PCR } \\
\hline & $26 S$ & 138 & 34 & 9 & $\begin{array}{l}\text { Mouse blood and } \\
\text { tissue (21) }\end{array}$ & 100 & 100 & ND & $\begin{array}{l}\text { Arastehfar } \\
\text { et al., } 2018\end{array}$ \\
\hline & $26 S$ & 3 & 297 & ND & ND & 100 & 100 & ND & $\begin{array}{l}\text { Arastehfar } \\
\text { et al., 2019a }\end{array}$ \\
\hline & $26 S$ & 35 & 1149 & 47 & ND & 100 & 100 & ND & $\begin{array}{l}\text { Arastehfar } \\
\text { et al., 2019c }\end{array}$ \\
\hline \multicolumn{10}{|c|}{ Real-time PCR } \\
\hline & ITS2 & 44 & 92 & 5 & ND & 100 & 100 & 10 & $\begin{array}{l}\text { Kordalewska } \\
\text { et al., } 2017\end{array}$ \\
\hline & ITS2 & 17 & 40 & 31 & Swab (365) & 89 & 99 & 1 & $\begin{array}{l}\text { Leach et al., } \\
2018\end{array}$ \\
\hline & & 58 & & & Sponge (258) & 100 & 89 & 1 & $\begin{array}{l}\text { Leach et al., } \\
2018\end{array}$ \\
\hline & ITS2 & 47 & & & Swab (110) & 96 & 92 & 1 & $\begin{array}{l}\text { Leach et al., } \\
2019\end{array}$ \\
\hline & ITS2 & 73 & & & Swab (247) & 93.6 & 97.2 & 1 & $\begin{array}{l}\text { Ahmad et al., } \\
2019\end{array}$ \\
\hline & ITS1/2 & 10 & 103 & 13 & $\begin{array}{l}\text { Simulated sputum, } \\
\text { Urine, Wound } \\
\text { swabs, and Serum } \\
\text { (11) }\end{array}$ & 100 & 100 & 1 & $\begin{array}{l}\text { Lima et al., } \\
2019\end{array}$ \\
\hline & ITS2 & 32 & 18 & 54 & $\begin{array}{c}\text { Simulated urine, } \\
\text { Blood, and Swab } \\
\text { (30) }\end{array}$ & $93.3-100$ & 96 & $4-54$ & $\begin{array}{l}\text { Walchak et al., } \\
2020\end{array}$ \\
\hline & GPI & 155 & 18 & ND & Simulated serum (1) & 100 & 100 & 5 & $\begin{array}{l}\text { Alvarado et al., } \\
2021\end{array}$ \\
\hline & GPI & 8 & 62 & 2,123 & $\begin{array}{l}\text { Stool and water } \\
\text { samples (2073) }\end{array}$ & 100 & 100 & 13 & $\begin{array}{l}\text { Ibrahim et al., } \\
2021 a\end{array}$ \\
\hline & ITS & 4 & 113 & 8 & ND & 100 & 100 & 1 & $\begin{array}{l}\text { Jafarian et al., } \\
2020\end{array}$ \\
\hline LAMP & $\begin{array}{l}\text { Pyruvate } \\
\text { synthase }\end{array}$ & 20 & 32 & 13 & ND & 100 & 100 & 20 & $\begin{array}{l}\text { Yamamoto } \\
\text { et al., } 2018\end{array}$ \\
\hline
\end{tabular}




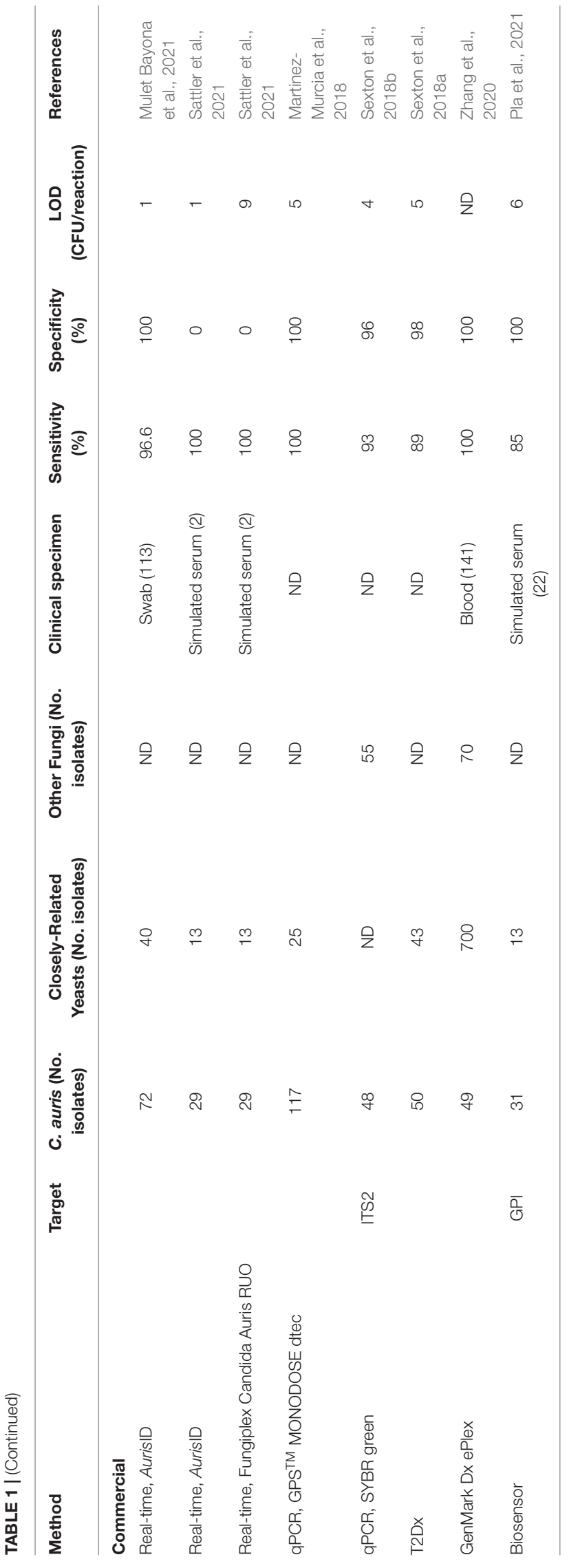

resource-poor settings, direct PCR methods appear not to be widely adopted either due to the potential for contamination, the difficulties of recording minor variations in the gel bands or the unavailability of validation data needed for a laboratorydeveloped test (LDT) (Bockstahler, 1994; Millar et al., 2002; Hoorfar et al., 2004). A commercial multiplex nucleic acid test panel that includes $C$. auris, received FDA approval on March 18, 2020; we did not find any independent evaluation of this product in peer-reviewed publication (BioFire ${ }^{\circledR}$ Blood Culture Identification 2 (BCID2) Panel, FilmArray ${ }^{\circledR} 2.0$ or FilmArray ${ }^{\circledR}$ Torch systems, bioMérieux, Inc., Durham, NC, United States).

Yamamoto et al. (2018) developed a loop-mediated isothermal amplification (LAMP)-based approach to detect C. auris. LAMP forward/reverse primers targeting $C$. auris the pyruvate: ferredoxin oxidoreductase domain from uncharacterized protein (NCBI CJI97_003625, Gene ID 40028770) were tested in PCR at $56^{\circ} \mathrm{C}$ for $90 \mathrm{~min}$ and the product visualized with a turbidimeter (Yamamoto et al., 2018). The assay had an excellent limit of detection (LOD) (20 copies/reaction) and specificity (100\%) with a large panel of $C$. auris and other fungi, positive C. auris identification from a clinical swab, and simulated environmental specimens (Yamamoto et al., 2018). Surprisingly, C. auris LAMP assay has not seen broader adaptation, perhaps because test kit manufacturers appear to be unenthused about LAMP technology (Cantera et al., 2019).

\section{Candida auris REAL-TIME PCR}

Kordalewska et al. (2017) described a real-time PCR assay for C. auris (Table 1). The new assay targeted Candida ribosomal genes for specific primers used either for direct PCR and detection of variable amplicon sizes or for real-time PCR and melting curve analysis of the double-strand-specific dye SYBR ${ }^{\circledR}$ Green I (Wittwer et al., 2013). The investigators reported $100 \%$ accuracy (100\% sensitivity and specificity) for C. auris from closely related species based on a proficiency panel of 44. C. auris and 97 other yeast isolates (Kordalewska et al., 2017). Further evaluation and modification of the assay by the Perlin laboratory and CDC investigators allowed direct detection of $C$. auris from patient swabs with 93\% sensitivity and 96\% specificity (Sexton et al., 2018b). This milestone marked the availability of a rapid C. auris real-time PCR test for surveillance purposes with the accompanying validation data required of an LDT. Within 3 months of the publication of the new real-time assay, one of us (SC) led a team that developed and validated a TaqMan-based real-time PCR assay targeting the ribosomal ITS2 of C. auris (Leach et al., 2018). The validation study comprised 623 surveillance samples, including 365 patient swabs and 258 environmental sponges. We found 49 swabs and 58 sponge samples positive, with 89 and $100 \%$ clinical sensitivity vis-a-vis culture-positive results (Leach et al., 2018). The distinguishing features of our assay vis-à-vis earlier publication from Perlin laboratory were the use of TaqMan probe chemistry, higher sensitivity (with an LOD of 1 C. auris CFU/PCR), the inclusion of all known clades of $C$. auris as reported by whole-genome sequencing, 
and direct utilization of the test for detection of C. auris from large numbers of surveillance samples (Kordalewska et al., 2017; Leach et al., 2018; Sexton et al., 2018b). We further expanded our manual assay to an automated sample-to-result real-time C. auris PCR assay using the BD Max open system (Leach et al., 2019). The new assay, with culture as gold standard, yielded 96\% clinical sensitivity, and 94\% clinical accuracy with 110 patient surveillance samples (Leach et al., 2019). The new assay appeared promising for broader adaptability and availability of high throughput surveillance testing (Leach et al., 2019). CDC investigators adapted our manual assay to an even higher throughput platform by automating the extraction steps and achieved diagnostic sensitivity and specificity of 93.6 and $97.2 \%$, respectively (Ahmad et al., 2019). Both manual and semiautomated $C$. auris assays developed by our group were adopted by other laboratories, including the CDC Antifungal Resistance Lab Network (personal communications) (Caceres et al., 2019; Malczynski et al., 2020; Pacilli et al., 2020; CDC, 2021a). A few months before submission/publication of our BD Max assay, Lima et al. (2019) described a BD Max assay for C. auris. The authors designed primers to target many fungal ribosomal genes and tested a collection of fungi and bacteria and 50 contrived clinical specimens to report $100 \%$ clinical sensitivity and specificity (Lima et al., 2019). The authors indicated that their primer-design strategy was superior to other reported assays, and the new assay was widely applicable. However, only 10 C. auris isolates and no $C$. auris positive clinical or surveillance samples were tested during the validation steps (Lima et al., 2019). Further information is awaited about the performance and adoption of the assay in other laboratories.

In 2020-2021, several additional laboratories described realtime PCR assays for C. auris (Walchak et al., 2020; Alvarado et al., 2021; Ibrahim et al., 2021a; Table 1). Commercial primers and probes, melting curve analysis, and validation with limited $C$. auris isolates and contrived clinical samples allowed $\leq 100 \mathrm{CFU} /$ reaction sensitivity from blood and urine (Walchak et al., 2020). A similar melting curve approach using primers against GPI-modified protein-encoding genes allowed specific identification and detection of $C$. auris with an LOD of $5 \mathrm{CFU} /$ reaction for isolates, $20 \mathrm{CFU} /$ reaction from spiked blood and serum (Alvarado et al., 2021). A TaqMan-chemistry assay with an ITS2-specific probe achieved LOD $1 \mathrm{CFU} /$ reaction when four $C$. auris isolates and other fungal and bacterial strains were tested (Jafarian et al., 2020). Another study utilizing a GPI-target probe with TaqMan-chemistry and simulated samples achieved an LOD of $13 \mathrm{C}$. auris CFU/qPCR reaction (Ibrahim et al., 2021a). The number of publications suggests real-time PCR is a preferred approach for rapid identification of $C$. auris from clinical, surveillance, and environmental samples. However, in the absence of head-to-head comparisons, it is not clear if SYBR ${ }^{\circledR}$ Green I or TaqMan chemistry, or a particular real-time machine, are preferable for $C$. auris real-time PCR assays. A few studies not involving $C$. auris describe the relative merits of various real-time probes. Moreover, a process was published to compare in-development real-time platforms; we refer the readers to these studies to make an informed choice about primers, probes, and a platform suitable for their laboratory needs (Van Poucke et al.,
2012; Polinski et al., 2013; Ahrberg and Neužil, 2015; Cantera et al., 2019).

\section{Candida auris REAL-TIME PCR KITS}

AurisID ${ }^{\circledR}$ is a commercial kit with ready-made reagents for qPCR to identify C. auris from fungal culture (OLM Diagnostics, Newcastle upon Tyne, England) (Table 1). A retrospective evaluation with $C$. auris positive swab samples reported 96.6\% sensitivity (Mulet Bayona et al., 2021). In a second study, Auris ID ${ }^{\circledR}$ detected $C$. auris with an LOD of 1 genome copy/reaction but gave false positives with high DNA amounts of the C. haemulonii, C. duobushaemulonii, and C. pseudohaemulonii (Sattler et al., 2021). Fungiplex ${ }^{\circledR}$ Candida Auris is a real-time, research use only (RUO) PCR assay for the rapid detection of $C$. auris in hospital hygiene applications including ready-made reagents for qPCR (Bruker Daltonics GmbH \& Co. KG. Bremen, Germany). An independent evaluation reported the Fungiplex ${ }^{\circledR}$ Candida Auris kit LOD to be 9 copies/reaction, much lower than AurisID ${ }^{\circledR}(\mathrm{LOD}=$ one copy/reaction) and $100 \%$ specificity for five C. auris isolates tested (Sattler et al., 2021). The investigators also tested Fungiplex ${ }^{\circledR}$ Candida Auris in "off-label use" with blood samples spiked with two C. auris isolates to obtain $\sim 45$ viable CFU/reaction (Sattler et al., 2021). All three commercial ready-to-use real-time PCR reagent kits do not disclose primer and probe details, which may or may not impact their future use as new C. auris clades are discovered. None of these kits have current regulatory approval for routine use in diagnostic laboratories.

\section{DIFFERENTIAL AND SELECTIVE MEDIA}

Differential culture media continue to be widely used in busy clinical laboratories. CHROMagar ${ }^{\mathrm{TM}}$ Candida Plus is a new chromogenic differential medium (Table 2). A comparative evaluation with HiCrome C. auris MDR selective agar, CandiSelect, CHROMagar ${ }^{\mathrm{TM}}$ Candida, and Chromatic Candida commercial media revealed C. auris colonies develop a speciesspecific coloration, as do closely related pathogenic species C. pseudohaemulonii and Candida vulturna (de Jong et al., 2021). In a similarly designed laboratory evaluation, CHROMagar ${ }^{\mathrm{TM}}$ Candida Plus agar was judged to be an excellent alternative to conventional mycological media for the screening of patients with $C$. auris, as only Candida diddensiae yielded a similar coloration (Borman et al., 2021). An earlier evaluation of CHROMagar ${ }^{\mathrm{TM}}$ Candida Plus found $100 \%$ sensitivity and specificity for $C$. auris when 14 surveillance samples were tested (Mulet Bayona et al., 2020). Even in an off-label modification, CHROMagar Candida was reported to offer differentiation between $C$. auris and C. haemulonii complex (Kumar et al., 2017). Thus, CHROMagar Candida Plus agar, and possibly other commercial differential media, hold promise for presumptive identification of $C$. auris when the laboratory confirms the identification with MALDI-TOF MS or another confirmatory test as per the manufacturer's recommendation. 
TABLE 2 | Candida auris identification by mass spectrometry and other biochemical methods.

\begin{tabular}{|c|c|c|c|c|c|c|c|}
\hline Method & $\begin{array}{l}\text { C. auris (No. } \\
\text { isolates) }\end{array}$ & $\begin{array}{c}\text { Closely-Related } \\
\text { Yeasts (No. isolates) }\end{array}$ & $\begin{array}{c}\text { Other Yeasts (No. } \\
\text { isolates) }\end{array}$ & $\begin{array}{l}\text { Clinical } \\
\text { specimen } \\
\text { (No.) }\end{array}$ & Sensitivity (\%) & Specificity (\%) & References \\
\hline \multicolumn{8}{|l|}{ Mass spectrometry } \\
\hline Bruker & 90 & 12 & ND & ND & 100 & 100 & $\begin{array}{c}\text { Kathuria et al., } \\
2015\end{array}$ \\
\hline Bruker & 82 & 11 & ND & ND & 100 & 100 & Girard et al., 2016 \\
\hline Bruker, CMdb database & 33 & 62 & 16 & ND & 100 & 100 & Bao et al., 2018 \\
\hline MALDI & 3 & 298 & ND & ND & 100 & 100 & $\begin{array}{c}\text { Arastehfar et al., } \\
2019 a\end{array}$ \\
\hline MALDI, PXD016387 database & 300 & 8 & ND & ND & 100 & 100 & $\begin{array}{l}\text { Ceballos-Garzon } \\
\text { et al., } 2020\end{array}$ \\
\hline Autof MS 1000 & 2 & 1216 & ND & ND & 100 & 100 & Yi et al., 2021 \\
\hline Vitek MS & 2 & 1216 & ND & ND & 100 & 100 & Yi et al., 2021 \\
\hline Biotyper & 61 & ND & ND & ND & $75.4-83.6$ & ND & Kwon et al., 2019 \\
\hline Vitek MS & 61 & ND & ND & ND & $93.4-96.7$ & ND & Kwon et al., 2019 \\
\hline \multicolumn{8}{|l|}{ Differential media } \\
\hline CHROMagarTM with Pal's medium & 15 & 13 & ND & ND & 100 & 100 & Kumar et al., 2017 \\
\hline CHROMagarTM Candida Plus & 37 & 58 & ND & swab (23) & 100 & 100 & $\begin{array}{l}\text { Mulet Bayona et al. } \\
2020\end{array}$ \\
\hline CHROMagar $^{T M}$ Candida Plus & 10 & 52 & ND & ND & ND & 98 & Borman et al., 2021 \\
\hline CHROMagar $^{\top \mathrm{M}}$ Candida Plus & 9 & 35 & ND & ND & 90 & 100 & $\begin{array}{c}\text { de Jong et al., } \\
2021\end{array}$ \\
\hline \multicolumn{8}{|l|}{ Selective media } \\
\hline Selective Auris Medium & 133 & 446 & ND & $\begin{array}{c}\text { Bactec blood } \\
\text { culture broth } \\
\text { (40) }\end{array}$ & 100 & 100 & Das et al., 2021 \\
\hline Specific C. auris (SCA) Medium & 7 & 128 & 50 & stool (200) & 100 & 100 & $\begin{array}{l}\text { Ibrahim et al., } \\
\text { 2021b }\end{array}$ \\
\hline
\end{tabular}


Welsh et al. (2017) described the first selective medium when they reported $C$. auris growth at an elevated temperature $\left(40^{\circ} \mathrm{C}\right)$ and salinity $(10 \% \mathrm{wt} / \mathrm{vol})$ in the Sabouraud or yeast nitrogen base broths with dulcitol or mannitol as the carbon source. The high salt medium had an excellent performance in the selective enrichment of $C$. auris cells from patient and environmental surveillance samples (Zhu et al., 2020; Sexton et al., 2021). A modified Selective Auris Medium (SAM) was recently described with YPD agar comprising $12.5 \% \mathrm{NaCl}$ and $9 \mathrm{mM}$ ferrous sulfate and incubation at $42^{\circ} \mathrm{C}$ (Das et al., 2021). Another variation of selective medium described by Walsh is termed SCA (specific C. auris) medium, incorporating crystal violet to prevent the growth of Candida tropicalis (Ibrahim et al., 2021b). Both SAM and SCA are reported to improve the original C. auris selective medium, but independent confirmations are not yet available.

In laboratories without access to ITS sequencing and MALDITOF MS, it is convenient to use manual or automated biochemical panels and systems to confirm the identification of yeast isolated from culture. Earlier reports and recent reevaluations found incomplete or incorrect identifications of C. auris by the API ID $32 \mathrm{C}$ system (version 4.0 database), AuxaColor $^{\mathrm{TM}} 2$ (Bio-Rad Laboratories, Marnes-la-Coquette, France), Vitek 2 (bioMérieux, Marcy l'Étoile, France), BD Phoenix (BD Diagnostics, Sparks, MD, United States), and RapID Yeast Plus (Remel, Thermo Fisher Scientific, Lenexa, KS, United States) (Won et al., 2014; Kathuria et al., 2015; Kim et al., 2016; Ruiz Gaitan et al., 2017; Iguchi et al., 2018; Sharp et al., 2018; Snayd et al., 2018; Ambaraghassi et al., 2019; Tan et al., 2019; CDC, 2021b; Du et al., 2021; Table 2). A recent report on API ID $32 \mathrm{C}$ concluded that $C$. auris could be identified if the percentage of positive reactions is registered in the database or calculated manually (Du et al., 2021). It appears these panels and systems need further refinements and evaluation to assess their utility for the identification of rare yeasts, including C. auris (Du et al., 2021). It might also be prudent for the end users to promptly install the latest product updates from the manufacturers and review any new information on approvals and evaluations.

\section{Candida auris ANTIFUNGAL RESISTANCE TESTING}

Antifungal susceptibility testing (AFST) of $C$. auris is performed with CLSI or EUCAST methods and commercial devices (Chowdhary et al., 2014, 2018; Arendrup et al., 2017; Bidaud et al., 2019; Escandon et al., 2019; Kwon et al., 2019; O’Brien et al., 2020; Zhu et al., 2020; CDC, 2021a). Several new drugs in development were also tested for their efficacy against $C$. auris using standard AFST (Arendrup et al., 2018; Ghannoum et al., 2020). A few studies describe antifungal combination testing for C. auris using LDTs (Fakhim et al., 2017; Bidaud et al., 2019; O'Brien et al., 2020). The literature on C. auris antifungal testing is voluminous, and discussion of these publications is not possible here. The focus is on the evaluation of established or new laboratory tests. Nevertheless, it is incumbent upon laboratories to perform both identification and antifungal testing for $C$. auris as part of their diagnostic service. The drug-resistance pattern in C. auris remains variable. Also, regional patterns have been observed for fluconazole and other triazoles, echinocandins, and amphotericin B (Chowdhary et al., 2018; Escandon et al., 2019). There is emerging evidence about the utility of susceptibility testing in selecting appropriate antifungal drugs in the management of patients (Alatoom et al., 2018; Chen et al., 2018; Dewaele et al., 2020). Lessons learned from C. auris outbreak investigations included a vital role for antifungal susceptibility data for surveillance purposes, including monitoring emerging drug resistance patterns in the community (Mulet Bayona et al., 2020; Ostrowsky et al., 2020; Zhu et al., 2020; Tian et al., 2021). AFST test innovations for $C$. auris remain sparse, with just one report describing same-day identification and echinocandin-resistance testing using MALDI-TOF MS (Vatanshenassan et al., 2019). Further confirmations and correlation of the new test approach with standard AFST are not yet available. The phenotype based CLSI, EUCAST, and commercial AFST tests are slow. Ideally, phenotype tests should be preceded by rapid DNA tests for drug-resistant $C$. auris, ensuring timely treatment of infected patients and effective pathogen control measures. In promising developments, Perlin laboratory described a molecular beaconbased platform for detecting FKS1 (echinocandins) and ERG11 (azoles) mutations in C. auris isolates and patient swab samples (Hou et al., 2019; Kordalewska et al., 2019). The molecular tests for drug resistance are desirable as surrogates for standard AFST tests standalone or multiplexed with rapid ID tests for C. auris. Molecular platforms offer flexibility to target new mutations encountered in drug-resistant C. auris.

\section{Candida auris DIAGNOSTIC ALGORITHM}

Candida auris colonization and infection among hospitalized patients and long-term care residents have become a global problem, with localized outbreaks reported from several countries. Several laboratory modes of operation are possible regarding pathogen isolation, rapid identification, susceptibility testing, and genotyping. Figure 1 provides a conceptual illustration of testing method differences between lowcomplexity and moderate- to high-complexity laboratories. A significant challenge for specialized diagnostic mycology laboratories concerns supporting $C$. auris surveillance and outbreak investigations. Such a service is available in large bacteriology laboratories but seldom needed for fungal pathogens. Consequently, many clinical recommendations and guidelines were published for laboratories that work with or want to expand their services for C. auris (Lockhart et al., 2017; Tsay et al., 2018; Caceres et al., 2019; Kenters et al., 2019). In the United States, the latest versions of the CLSI M-54 document and the Manual of Clinical Microbiology, peer-recommended guidelines for diagnostic microbiology laboratories, do not have C. auris-specific guidelines for isolation and identification (Carroll et al., 2019; CLSI, 2021). Early in 2017, we devised an algorithm which has been modified regularly since then to cope with an unprecedented volume of surveillance and clinical samples of $C$. auris. Alternate laboratory approaches are shown with dotted lines. We share the scheme hoping it will 


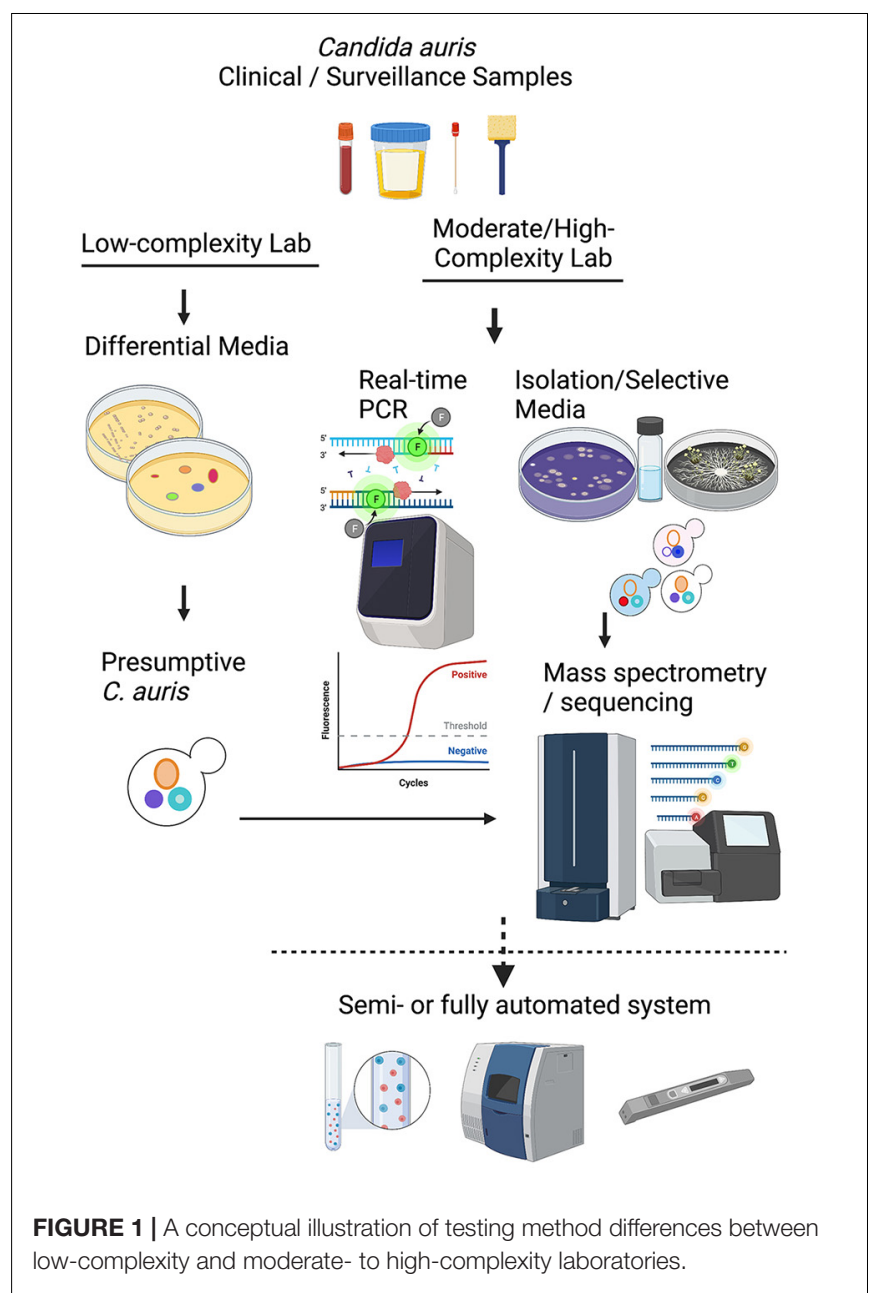

help other laboratories to modify their workflows to suit local needs (Figure 2).

\section{Candida auris DIAGNOSTICS ON THE HORIZON}

Among commercial products likely to be available soon, T2MR (T2 magnetic resonance) is a portable system that detects candidemia by measuring signals from PCR-amplified Candida nanoparticle clusters in the blood directly within $3 \mathrm{~h}$ (Neely et al., 2013; Mylonakis et al., 2015). In 2018, CDC investigators evaluated a T2Cauris panel (T2 Biosystems, Lexington, MA, United States) with axilla/groin swab samples and reported $89 \%$ sensitivity and $98 \%$ specificity for detecting C. auris (Sexton et al., 2018a; Table 2). The T2Biosystems ${ }^{\circledR}$ website states that T2Cauris is not cleared for diagnostic testing and is available for research use only (RUO). MONODOSE dtec-qPCR C. auris is a commercial ready-to-use qPCR kit for pathogen detection (Genetic PCR Solutions ${ }^{\mathrm{TM}}$, Alicante, Spain). The manufacturer completed a validation study with academic partners according to UNE-EN ISO/IEC 17025:2005 standard (Martinez-Murcia et al., 2018). The investigators reported MONODOSE dtec-qPCR
C. auris passed validation in two independent laboratories and is ready to undergo clinical evaluation (Martinez-Murcia et al., 2018). Among new sample-to-answer systems, ePlex BCID-FP is an investigational use only proprietary reagent test panel for 15 Candida species used with a proprietary ePlex System (GenMark Diagnostics, Inc., Carlsbad, CA, United States). A multilaboratory evaluation with 3 C. auris isolates and 49 contrived blood samples obtained $100 \%$ sensitivity and specificity (Zhang et al., 2020). Another sample-to-answer approach based on an oligonucleotide-functionalized gated nanosystem for C. auris achieved $85 \%$ sensitivity and $100 \%$ specificity in limited testing with 22 blood samples (Pla et al., 2021). Mass spectrometry systems from manufacturers other than Bruker are also available and in use in clinical laboratories. A minimal evaluation with two C. auris isolates reported equal efficacy of Vitek MS and Autof MS 1000 systems (Yi et al., 2021). It is safe to say that any MALDI-TOF MS machine will provide identification of C. auris provided enough representative isolates encompassing all known clades are included in the database to train the decision algorithm (van Belkum et al., 2017). Limited but promising results are also being published on sample processing and machine learning applications to MALDI platforms, which will benefit C. auris diagnostics eventually (Muthu et al., 2018; Weis et al., 2020; De Bruyne et al., 2021).

\section{Candida auris BIOSAFETY, DISINFECTANTS, AND ADVISORIES}

Candida auris poses unique occupational risks for laboratory personnel due to potential exposure to multidrug-resistant organisms. The reported persistence of $C$. auris on inanimate objects requires focused efforts at environmental decontamination. No C. auris-specific guidelines are available in the latest edition of BMBL Biosafety in Microbiological and Biomedical Laboratories (DHH, 2020). CDC and many state and local jurisdictions in the United States have issued C. auris advisories for healthcare professionals. The guidance information is regularly updated online for easy consultation. The United States EPA's (Environmental Protection Agency) List $\mathrm{P}$ includes 23 disinfectant products with claims about their ability to kill C. auris (EPA, 2021). We follow institutional biosafety guidelines for BSL 2 laboratories. Our additional precautions include frequent changes of hand gloves and disposable lab apparel. The laboratory work surfaces are decontaminated pre- and post-procedure with freshly prepared 10\% bleach solution, followed by $70 \%$ ethanol. We secure fungal cultures in secondary containers for transfer and incubation within the laboratory. Periodic sampling of space and instruments are done by $C$. auris real-time PCR and culture to check for any inadvertent fungal contamination.

\section{Candida auris TEST WISH LIST}

The availability of rapid C. auris DNA tests onsite remain severely restricted, especially in resource-poor settings. The results are 


\section{Candida auris Suggested Test Plans}

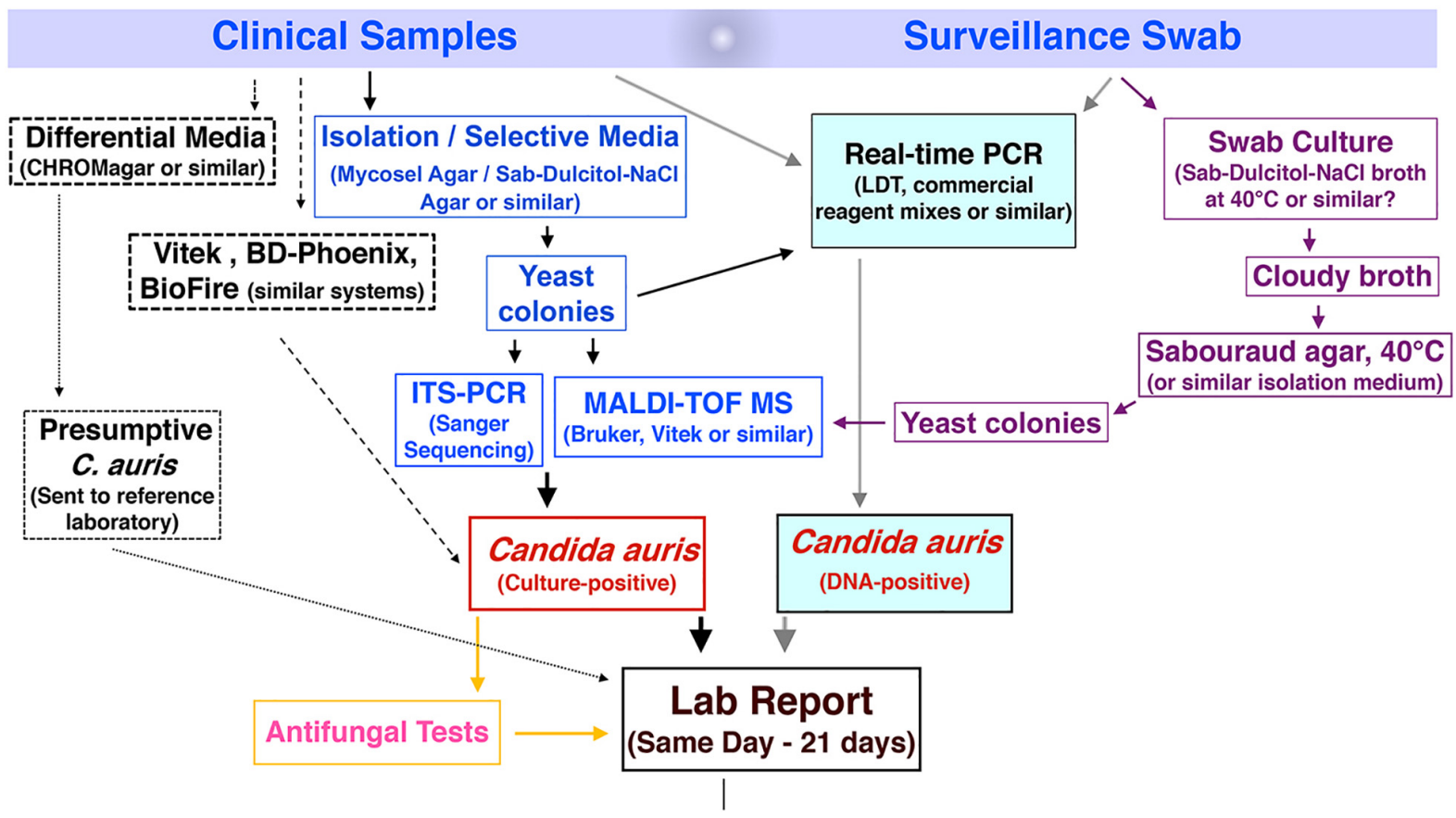

Rapid Notifications - Hospital / Facility / Infection Control / Public Health

FIGURE 2 | Workflow algorithm for high-volume surveillance and clinical sample testing of C. auris. Dotted lines indicate alternate laboratory approaches.

available only after $24-72 \mathrm{~h}$, assuming samples are sent out for reference testing. DNA tests are challenging for many frontline laboratories and long-term care facilities due to a lack of equipment and trained personnel. MALDI-TOF MS assays work best with isolated $C$. auris colonies, but the time required delays diagnosis by 3-7 days on average (Zhu et al., 2020). Frontline laboratories need rapid and facile onsite testing of $C$. auris to inform their efforts at identification, surveillance, patient isolation, admission screening, and environmental control (Durante et al., 2018; Wang et al., 2020). Thus, there is an unmet, urgent need for simple C. auris tests, especially for surveillance samples. Lateral flow assays (LFAs), also known as lateral flow immunoassay or immunochromatographic assay, could be a good choice as they are rapid, cheap, stable, and easy-to-implement for presumptive identification of microbes (Koczula and Gallotta, 2016; Boutal et al., 2018). At the other end of the service spectrum, many hospital laboratories already use multiplex test panels for Clostridioides difficile and carbapenemresistant Enterobacterales (CRE), and synergy of such panels with C. auris testing would be welcome (Binnicker, 2015; Crobach et al., 2016; Kost et al., 2017; McDonald et al., 2018; Bogaerts et al., 2020; CDC, 2021c). Current AFST services are inadequate as turnaround time is woefully inadequate, and new test formats/devices are needed for faster reporting and AFST-directed treatment of $C$. auris infections. Laboratory surveillance is crucial for monitoring and control of C. auris outbreaks. C. auris genome analysis has a proven role in the control of hospital outbreaks by pinpointing the common source (Eyre et al., 2018; Theodoropoulos et al., 2020). However, fungal genome sequencing and analysis remain beyond the capabilities of most diagnostic laboratories. Therefore, local outbreak investigations require diagnostic laboratories to quickly access regional and national collaborative networks with standardized C. auris sequencing tools (Ladner et al., 2019; Mintzer et al., 2019; NIHR Global Health Research Unit on Genomic Surveillance of AMR, 2020).

\section{AUTHOR CONTRIBUTIONS}

ED: draft preparation, review and editing, visualization. SC: supervision, conceptualization, and review and editing. VC: supervision, conceptualization, draft preparation, and review and editing, visualization. All authors approved the final version.

\section{FUNDING}

Supported in part by a Centers for Disease Control and Prevention-Antibiotic Resistance Lab Network grant 
(NU50CK000423) and a grant (1R21AI156573-01A1) from the National Institutes of Health. The contents are solely the responsibility of the authors and do not necessarily represent the official views of the Centers for Disease Control and Prevention or the Department of Health and Human Services.

\section{REFERENCES}

Ahmad, A., Spencer, J. E., Lockhart, S. R., Singleton, S., Petway, D. J., Bagarozzi, D. A., et al. (2019). A high-throughput and rapid method for accurate identification of emerging multidrug-resistant Candida auris. Mycoses 62, 513-518. doi: $10.1111 /$ myc. 12907

Ahrberg, C. D., and Neužil, P. (2015). Doubling Throughput of a Real-Time PCR. Sci. Rep. 5:12595. doi: 10.1038/srep12595

Alatoom, A., Sartawi, M., Lawlor, K., AbdelWareth, L., Thomsen, J., Nusair, A., et al. (2018). Persistent candidemia despite appropriate fungal therapy: First case of Candida auris from the United Arab Emirates. Int. J. Infect. Dis. 70, 36-37. doi: 10.1016/j.ijid.2018.02.005

Alcoba-Florez, J., Mendez-Alvarez, S., Cano, J., Guarro, J., Perez-Roth, E., and del Pilar Arevalo, M. (2005). Phenotypic and molecular characterization of Candida nivariensis sp. nov., a possible new opportunistic fungus. J. Clin. Microbiol. 43, 4107-4111. doi: 10.1128/JCM.43.8.4107-4111.2005

Alvarado, M., Bartolome Alvarez, J., Lockhart, S. R., Valentin, E., Ruiz-Gaitan, A. C., Eraso, E., et al. (2021). Identification of Candida auris and related species by multiplex PCR based on unique GPI protein-encoding genes. Mycoses 64, 194-202. doi: $10.1111 /$ myc. 13204

Ambaraghassi, G., Dufresne, P. J., Dufresne, S. F., Vallieres, E., Munoz, J. F., Cuomo, C. A., et al. (2019). Identification of Candida auris by Use of the Updated Vitek 2 Yeast Identification System, Version 8.01: a Multilaboratory Evaluation Study. J. Clin. Microbiol. 57, e884-e819. doi: 10.1128/JCM.008 84-19

Arastehfar, A., Daneshnia, F., Kord, M., Roudbary, M., Zarrinfar, H., Fang, W., et al. (2019a). Comparison of 21-Plex PCR and API 20C AUX, MALDI-TOF MS, and rDNA sequencing for a wide range of clinically isolated yeast species: Improved identification by combining 21-Plex PCR and API 20C AUX as an alternative strategy for developing countries. Front. Cell. Infect. Microb. 9:21. doi: $10.3389 /$ fcimb.2019.00021

Arastehfar, A., Fang, W., Badali, H., Vaezi, A., Jiang, W., Liao, W., et al. (2018). Low-Cost Tetraplex PCR for the Global Spreading Multi-Drug Resistant Fungus, Candida auris and Its Phylogenetic Relatives. Front. Microbiol. 9:1119. doi: $10.3389 /$ fmicb.2018.01119

Arastehfar, A., Fang, W., Daneshnia, F., Al-Hatmi, A. M., Liao, W., Pan, W., et al. (2019b). Novel multiplex real-time quantitative PCR detecting system approach for direct detection of Candida auris and its relatives in spiked serum samples. Future Microbiol. 14, 33-45. doi: 10.2217/fmb-2018-0227

Arastehfar, A., Fang, W., Pan, W., Lackner, M., Liao, W., Badiee, P., et al. (2019c). YEAST PANEL multiplex PCR for identification of clinically important yeast species: stepwise diagnostic strategy, useful for developing countries. Diagn. Microbiol. Infect. Dis. 93, 112-119. doi: 10.1016/j.diagmicrobio.2018.09.007

Arendrup, M. C., Chowdhary, A., Astvad, K. M. T., and Jorgensen, K. M. (2018). APX001A In Vitro Activity against Contemporary Blood Isolates and Candida auris Determined by the EUCAST Reference Method. Antimicrob. Agents Chemother. 62, e1225-e1218. doi: 10.1128/AAC.01225-18

Arendrup, M. C., Prakash, A., Meletiadis, J., Sharma, C., and Chowdhary, A. (2017). Comparison of EUCAST and CLSI reference microdilution MICs of eight antifungal compounds for Candida auris and associated tentative epidemiological cutoff values. Antimicrob. Chemother. 61, e417-e485. doi: 10.1128/AAC.00485-17

Bao, J. R., Master, R. N., Azad, K. N., Schwab, D. A., Clark, R. B., Jones, R. S., et al. (2018). Rapid, Accurate Identification of Candida auris by Using a Novel Matrix-Assisted Laser Desorption Ionization-Time of Flight Mass Spectrometry (MALDI-TOF MS) Database (Library). J. Clin. Microbiol. 56, e1700-e1717. doi: 10.1128/JCM.01700-17

Bidaud, A., Botterel, F., Chowdhary, A., and Dannaoui, E. (2019). In vitro antifungal combination of flucytosine with amphotericin B, voriconazole, or

\section{ACKNOWLEDGMENTS}

We thank YanChun Zhu, Lynn Leach, and Brittany O’Brien for their contributions to methods development, evaluations, and discussions about $C$. auris testing. Kimberly McClive-Reed is thanked for editorial comments.

micafungin against Candida auris shows no antagonism. Antimicrob. Agents Chemother. 2019:63. doi: 10.1128/AAC.01393-19

Binnicker, M. J. (2015). Multiplex Molecular Panels for Diagnosis of Gastrointestinal Infection: Performance, Result Interpretation, and CostEffectiveness. J. Clin. Microbiol. 53, 3723-3728. doi: 10.1128/JCM.0210315

Bockstahler, L. E. (1994). Overview of international PCR standardization efforts. PCR Methods Appl. 3, 263-267. doi: 10.1101/gr.3.5.263

Bogaerts, P., Berger, A. S., Evrard, S., and Huang, T. D. (2020). Comparison of two multiplex immunochromatographic assays for the rapid detection of major carbapenemases in Enterobacterales. J. Antimicrob. Chemother. 75, 1491-1494. doi: 10.1093/jac/dkaa043

Borman, A. M., Fraser, M., and Johnson, E. M. (2021). CHROMagarTM Candida Plus: A novel chromogenic agar that permits the rapid identification of Candida auris. Med. Mycol. 59, 253-258. doi: 10.1093/mmy/myaa049

Boutal, H., Vogel, A., Bernabeu, S., Devilliers, K., Creton, E., Cotellon, G., et al. (2018). A multiplex lateral flow immunoassay for the rapid identification of NDM-, KPC-, IMP- and VIM-type and OXA-48-like carbapenemaseproducing Enterobacteriaceae. J. Antimicrob. Chemother. 73, 909-915. doi: $10.1093 / \mathrm{jac} / \mathrm{dkx} 521$

Caceres, D. H., Forsberg, K., Welsh, R. M., Sexton, D. J., Lockhart, S. R., Jackson, B. R., et al. (2019). Candida auris: A Review of Recommendations for Detection and Control in Healthcare Settings. J. Fungi. 5:111. doi: 10.3390/jof504 0111

Cantera, J. L., White, H., Diaz, M. H., Beall, S. G., Winchell, J. M., Lillis, L., et al. (2019). Assessment of eight nucleic acid amplification technologies for potential use to detect infectious agents in low-resource settings. PLoS One 14:e0215756. doi: 10.1371/journal.pone.0215756

Carroll, K. C., Pfaller, M. A., Landry, M. L., McAdam, A. J., Patel, R., Richter, S. S., et al. (2019). Manual of Clinical Microbiology. Hoboken, NJ: John Wiley \& Sons, Inc. doi: 10.1128/9781555819842

Castanheira, M., Woosley, L. N., Diekema, D. J., Jones, R. N., and Pfaller, M. A. (2013). Candida guilliermondii and other species of Candida misidentified as Candida famata: assessment by vitek 2, DNA sequencing analysis, and matrixassisted laser desorption ionization-time of flight mass spectrometry in two global antifungal surveillance programs. J. Clin. Microbiol. 51, 117-124. doi: 10.1128/JCM.01686-12

CDC (2021a). How to Participate in CDC's AR Lab Network: Lab Testing. Centers for Disease Control and Prevention NCfEaZIDN. Atlanta, GA: Division of Healthcare Quality Promotion (DHQP).

CDC (2021b). Identification of Candida auris. Centers for Disease Control and Prevention NCfEaZIDN. Atlanta, GA: Division of Healthcare Quality Promotion (DHQP).

CDC (2021c). Laboratory Resources- Healthcare-associated Infection. Centers for Disease Control and Prevention NCfEaZIDN. Atlanta, GA: Division of Healthcare Quality Promotion (DHQP).

Ceballos-Garzon, A., Amado, D., Velez, N., Jimenez, A. M., Rodriguez, C., and Parra-Giraldo, C. M. (2020). Development and Validation of an in-House Library of Colombian Candida auris Strains with MALDI-TOF MS to Improve Yeast Identification. J. Fungi. 6:72. doi: 10.3390/jof6020072

Cendejas-Bueno, E., Kolecka, A., Alastruey-Izquierdo, A., Theelen, B., Groenewald, M., Kostrzewa, M., et al. (2012). Reclassification of the Candida haemulonii complex as Candida haemulonii (C. haemulonii group I), C. duobushaemulonii sp. nov. (C. haemulonii group II), and C. haemulonii var. vulnera var. nov.: three multiresistant human pathogenic yeasts. J. Clin. Microb. 50, 3641-3651. doi: 10.1128/JCM.02248-12

Chen, Y., Zhao, J., Han, L., Qi, L., Fan, W., Liu, J., et al. (2018). Emergency of fungemia cases caused by fluconazole-resistant Candida auris in Beijing. China. J. Infect. 77, 561-571. doi: 10.1016/j.jinf.2018.09.002 
Chowdhary, A., Anil Kumar, V., Sharma, C., Prakash, A., Agarwal, K., Babu, R., et al. (2014). Multidrug-resistant endemic clonal strain of Candida auris in India. Eur. J. Clin. Microbiol. Infect. Dis. 33, 919-926. doi: 10.1007/s10096-0132027-1

Chowdhary, A., Prakash, A., Sharma, C., Kordalewska, M., Kumar, A., Sarma, S., et al. (2018). A multicentre study of antifungal susceptibility patterns among 350 Candida auris isolates (2009-17) in India: role of the ERG11 and FKS1 genes in azole and echinocandin resistance. J. Antimicrob. Chemother. 73, 891-899. doi: 10.1093/jac/dkx480

Chowdhary, A., Sharma, C., Duggal, S., Agarwal, K., Prakash, A., Singh, P. K., et al. (2013). New clonal strain of Candida auris, Delhi, India. Emerg. Infect. Dis. 19, 1670-1673. doi: 10.3201/eid1910.130393

CLSI (2021). CLSI. Principles and procedures for detection and culture of fungi in clinical specimens. 2nd ed. CLSI guideline M54. Wayne, PA: Clinical and Laboratory Standards Institute.

Crobach, M. J., Planche, T., Eckert, C., Barbut, F., Terveer, E. M., Dekkers, O. M., et al. (2016). European Society of Clinical Microbiology and Infectious Diseases: update of the diagnostic guidance document for Clostridium difficile infection. Clin. Microbiol. Infect. 22(Suppl. 4), S63-S81. doi: 10.1016/j.cmi.2016.03.010

Das, S., Singh, S., Tawde, Y., Chakrabarti, A., Rudramurthy, S. M., Kaur, H., et al. (2021). A Selective Medium for Isolation and Detection of Candida auris, an Emerging Pathogen. J. Clin. Microbiol. 59, e326-e320. doi: 10.1128/JCM.0032620

De Bruyne, S., Speeckaert, M. M., Van Biesen, W., and Delanghe, J. R. (2021). Recent evolutions of machine learning applications in clinical laboratory medicine. Crit. Rev. Clin. Lab. Sci. 58, 131-152. doi: 10.1080/10408363.2020. 1828811

de Jong, A. W., Dieleman, C., Carbia, M., Mohd Tap, R., and Hagen, F. (2021). Performance of Two Novel Chromogenic Media for the Identification of Multidrug-Resistant Candida auris Compared with Other Commercially Available Formulations. J. Clin. Microbiol. 59, e3220-e3220. doi: 10.1128/JCM. 03220-20

Dewaele, K., Frans, J., Smismans, A., Ho, E., Tollens, T., and Lagrou, K. (2020). First case of Candida auris infection in Belgium in a surgical patient from Kuwait. Acta Clin. Belg. 75, 221-228. doi: 10.1080/17843286.2018.1555114

DHH (2020). Biosafety in Microbiological and Biomedical Laboratories. Services. U.S. Department of Health and Human Services.

Du, M., Hu, W., Tamura, T., Alshahni, M. M., Satoh, K., Yamanishi, C., et al. (2021). Investigation of the Physiological, Biochemical and Antifungal Susceptibility Properties of Candida auris. Mycopathologia 186, 189-198. doi: 10.1007/ s11046-020-00526-w

Durante, A. J., Maloney, M. H., Leung, V. H., Razeq, J. H., and Banach, D. B. (2018). Challenges in identifying Candida auris in hospital clinical laboratories: a need for hospital and public health laboratory collaboration in rapid identification of an emerging pathogen. Infect. Control. Hosp. Epidemiol. 39, 1015-1016. doi: $10.1017 /$ ice. 2018.133

Eddouzi, J., Hofstetter, V., Groenewald, M., Manai, M., and Sanglard, D. (2013). Characterization of a new clinical yeast species, Candida tunisiensis sp. nov., isolated from a strain collection from Tunisian hospitals. J. Clin. Microbiol. 51, 31-39. doi: 10.1128/JCM.01627-12

Emara, M., Ahmad, S., Khan, Z., Joseph, L., Al-Obaid Im, Purohit, P., et al. (2015). Candida auris candidemia in Kuwait, 2014. Emerg. Infect. Dis. 21:1091. doi: 10.3201/eid2106.150270

EPA (2021). List P: Antimicrobial Products Registered with EPA for Claims Against Candida Auris. Washington, DC: United States Environmental Protection Agency.

Escandon, P., Chow, N. A., Caceres, D. H., Gade, L., Berkow, E. L., Armstrong, P., et al. (2019). Molecular epidemiology of Candida auris in Colombia reveals a highly related, countrywide colonization with regional patterns in amphotericin B resistance. Clin. Infect. Dis. 68, 15-21. doi: 10.1093/cid/ciy411

Eyre, D. W., Sheppard, A. E., Madder, H., Moir, I., Moroney, R., Quan, T. P., et al. (2018). A Candida auris outbreak and its control in an intensive care setting. New Engl. J. Med. 379, 1322-1331. doi: 10.1056/NEJMoa171 4373

Fakhim, H., Chowdhary, A., Prakash, A., Vaezi, A., Dannaoui, E., Meis, J. F., et al. (2017). In vitro interactions of echinocandins with triazoles against multidrugresistant Candida auris. Antimicrob. Agents Chemother. 2017:61. doi: 10.1128/ AAC.01056- 17
Ghannoum, M., Arendrup, M. C., Chaturvedi, V. P., Lockhart, S. R., McCormick, T. S., Chaturvedi, S., et al. (2020). Ibrexafungerp: A Novel Oral Triterpenoid Antifungal in Development for the Treatment of Candida auris Infections. Antibiotics 2020:9. doi: 10.3390/antibiotics9090539

Ghosh, A. K., Paul, S., Sood, P., Rudramurthy, S. M., Rajbanshi, A., Jillwin, T. J., et al. (2015). Matrix-assisted laser desorption ionization time-of-flight mass spectrometry for the rapid identification of yeasts causing bloodstream infections. Clin. Microbiol. Infect. 21, 372-378. doi: 10.1016/j.cmi.2014.11.009

Girard, V., Mailler, S., Chetry, M., Vidal, C., Durand, G., van Belkum, A., et al. (2016). Identification and typing of the emerging pathogen Candida auris by matrix-assisted laser desorption ionisation time of flight mass spectrometry. Mycoses 59, 535-538. doi: 10.1111/myc.12519

Hoorfar, J., Wolffs, P., and Rådström, P. (2004). Diagnostic PCR: validation and sample preparation are two sides of the same coin. Apmis 112, 808-814. doi: 10.1111/j.1600-0463.2004.apm11211-1207.x

Hou, X., Lee, A., Jimenez-Ortigosa, C., Kordalewska, M., Perlin, D. S., and Zhao, Y. (2019). Rapid detection of ERG11-associated azole resistance and FKS-associated echinocandin resistance in Candida auris. Antimicrob. Agents Chemother. 63:e1811-18. doi: 10.1128/AAC.01811-18

Ibrahim, A., Baron, S. A., Yousfi, H., Hadjadj, L., Lalaoui, R., Morand, S., et al. (2021a). Development and standardization of a specific real-time PCR assay for the rapid detection of Candida auris. Eur. J. Clin. Microb. Infect. Dis. 2021:41768. doi: 10.1007/s10096-021-04176-8

Ibrahim, A., Peyclit, L., Abdallah, R., Khelaifia, S., Chamieh, A., Rolain, J. M., et al. (2021b). SCA Medium: A New Culture Medium for the Isolation of All Candida auris Clades. J. Fungi. 2021:7. doi: 10.20944/preprints202104.0658.v1

Iguchi, S., Mizushima, R., Kamada, K., Itakura, Y., Yoshida, A., Uzawa, Y., et al. (2018). The Second Candida auris Isolate from Aural Discharge in Japan. JPN J. Infect. Dis. 71, 174-175. doi: 10.7883/yoken.JJID.2017.466

Jafarian, H., Khodadadi, H., and Badiee, P. (2020). Development a hydrolysis probe-based quantitative PCR assay for the specific detection and quantification of Candida auris. Curr. Med. Mycol. 6, 50-56. doi: 10.18502/cmm.6.3.4665

Jensen, R. H., and Arendrup, M. C. (2011). Candida palmioleophila: characterization of a previously overlooked pathogen and its unique susceptibility profile in comparison with five related species. J. Clin. Microbiol. 49, 549-556. doi: 10.1128/JCM.02071-10

Kathuria, S., Singh, P. K., Sharma, C., Prakash, A., Masih, A., Kumar, A., et al. (2015). Multidrug-resistant Candida auris misidentified as Candida haemulonii: characterization by matrix-assisted laser desorption ionizationtime of flight mass spectrometry and DNA sequencing and its antifungal susceptibility profile variability by Vitek 2, CLSI broth microdilution, and Etest method. J. Clin. Microbiol. 53, 1823-1830. doi: 10.1128/JCM.00367-15

Kenters, N., Kiernan, M., Chowdhary, A., Denning, D. W., Pemán, J., Saris, K., et al. (2019). Control of Candida auris in healthcare institutions: Outcome of an International Society for Antimicrobial Chemotherapy expert meeting. Int. J. Antimicrob. Agents 54, 400-406. doi: 10.1016/j.ijantimicag.2019.08.013

Kim, G. Y., Jeon, J. S., and Kim, J. K. (2016). Isolation Frequency Characteristics of Candida Species from Clinical Specimens. Mycobiology 44, 99-104. doi: 10.5941/MYCO.2016.44.2.99

Kim, M. N., Shin, J. H., Sung, H., Lee, K., Kim, E. C., Ryoo, N., et al. (2009). Candida haemulonii and closely related species at 5 university hospitals in Korea: identification, antifungal susceptibility, and clinical features. Clin. Infect. Dis. 48, e57-e61. doi: 10.1086/597108

Koczula, K. M., and Gallotta, A. (2016). Lateral flow assays. Essays Biochem. 60, 111-120. doi: 10.1042/EBC20150012

Kordalewska, M., Lee, A., Zhao, Y., and Perlin, D. S. (2019). Detection of Candida auris Antifungal Drug Resistance Markers Directly from Clinical Skin Swabs. Antimicrob. Agents Chemother. 63, e1754-e1719. doi: 10.1128/AAC.017 54-19

Kordalewska, M., Zhao, Y., Lockhart, S. R., Chowdhary, A., Berrio, I., and Perlin, D. S. (2017). Rapid and accurate molecular identification of the emerging multidrug-resistant pathogen Candida auris. J. Clin. Microb. 55, 2445-2452. doi: 10.1128/JCM.00630-17

Kost, K., Yi, J., Rogers, B., and Jerris, R. (2017). Comparison of clinical methods for detecting carbapenem-resistant Enterobacteriaceae. Pract. Lab. Med. 8, 18-25. doi: 10.1016/j.plabm.2017.03.002

Kumar, A., Sachu, A., Mohan, K., Vinod, V., Dinesh, K., and Karim, S. (2017). Simple low cost differentiation of Candida auris from Candida haemulonii 
complex using CHROMagar Candida medium supplemented with Pal's medium. Rev. Iberoam. Micol. 34, 109-111. doi: 10.1016/j.riam.2016.11.004

Kwon, Y. J., Shin, J. H., Byun, S. A., Choi, M. J., Won, E. J., Lee, D., et al. (2019). Candida auris Clinical Isolates from South Korea: Identification. Antifung. Suscept. Genot. J. Clin. Microbiol. 57, e1618-e1624. doi: 10.1128/JCM.01624-18

Ladner, J. T., Grubaugh, N. D., Pybus, O. G., and Andersen, K. G. (2019). Precision epidemiology for infectious disease control. Nat. Med. 25, 206-211. doi: 10. 1038/s41591-019-0345-2

Leach, L., Russell, A., Zhu, Y., Chaturvedi, S., and Chaturvedi, V. (2019). A rapid and automated sample-to-result Candida auris real-time PCR assay for highthroughput testing of surveillance samples with the BD Max Open system. J. Clin. Microb. 57, e619-e630. doi: 10.1128/JCM.00630-19

Leach, L., Zhu, Y., and Chaturvedi, S. (2018). Development and validation of a realtime PCR assay for rapid detection of Candida auris from surveillance samples. J. Clin. Microb. 56, e1217-e1223. doi: 10.1128/JCM.01223-17

Lee, W. G., Shin, J. H., Uh, Y., Kang, M. G., Kim, S. H., Park, K. H., et al. (2011). First three reported cases of nosocomial fungemia caused by Candida auris. J. Clin. Microbiol. 49, 3139-3142. doi: 10.1128/JCM.00319-11

Lima, A., Widen, R., Vestal, G., Uy, D., and Silbert, S. (2019). A TaqMan ProbeBased Real-Time PCR Assay for the Rapid Identification of the Emerging Multidrug-Resistant Pathogen Candida auris on the BD Max System. J. Clin. Microbiol. 57, e1604-e1618. doi: 10.1128/JCM.01604-18

Lockhart, S. R., Etienne, K. A., Vallabhaneni, S., Farooqi, J., Chowdhary, A., Govender, N. P., et al. (2017). Simultaneous emergence of multidrug-resistant Candida auris on 3 continents confirmed by whole-genome sequencing and epidemiological analyses. Clin. Infect. Dis. 64, 134-140. doi: 10.1093/cid/ciw691

Magobo, R. E., Corcoran, C., Seetharam, S., and Govender, N. P. (2014). Candida auris-associated candidemia, South Africa. Emerg. Infect. Dis. 20:1250. doi: 10.3201/eid2007.131765

Malczynski, M., Dowllow, N., Rezaeian, S., Rios, J., Dirnberger, L., Zembower, J. A., et al. (2020). Optimizing a real-time PCR assay for rapid detection of Candida auris in nasal and axillary/groin samples. J. Med. Microb. 69, 824-829. doi: 10.1099/jmm.0.001207

Marklein, G., Josten, M., Klanke, U., Muller, E., Horre, R., Maier, T., et al. (2009). Matrix-assisted laser desorption ionization-time of flight mass spectrometry for fast and reliable identification of clinical yeast isolates. J. Clin. Microbiol. 47, 2912-2917. doi: 10.1128/JCM.00389-09

Martinez-Murcia, A., Navarro, A., Bru, G., Chowdhary, A., Hagen, F., and Meis, J. F. (2018). Internal validation of GPS() MONODOSE CanAur dtecqPCR kit following the UNE/EN ISO/IEC 17025:2005 for detection of the emerging yeast Candida auris. Mycoses 61, 877-884. doi: 10.1111/myc. 12834

McDonald, L. C., Gerding, D. N., Johnson, S., Bakken, J. S., Carroll, K. C., Coffin, S. E., et al. (2018). Clinical Practice Guidelines for Clostridium difficile Infection in Adults and Children: 2017 Update by the Infectious Diseases Society of America (IDSA) and Society for Healthcare Epidemiology of America (SHEA). Clin. Infect. Dis. 66, e1-e48. doi: 10.1093/cid/ciy149

Millar, B. C., Xu, J., and Moore, J. E. (2002). Risk assessment models and contamination management: implications for broad-range ribosomal DNA PCR as a diagnostic tool in medical bacteriology. J. Clin. Microbiol. 40, 15751580. doi: 10.1128/JCM.40.5.1575-1580.2002

Mintzer, V., Moran-Gilad, J., and Simon-Tuval, T. (2019). Operational models and criteria for incorporating microbial whole genome sequencing in hospital microbiology - A systematic literature review. Clin. Microbiol. Infect. 25, 10861095. doi: 10.1016/j.cmi.2019.04.019

Mulet Bayona, J. V., Salvador García, C., Tormo Palop, N., and Gimeno Cardona, C. (2020). Evaluation of a novel chromogenic medium for Candida spp. identification and comparison with CHROMagar ${ }^{\mathrm{TM}}$ Candida for the detection of Candida auris in surveillance samples. Diagn. Microbiol. Infect. Dis. 98:115168. doi: 10.1016/j.diagmicrobio.2020.115168

Mulet Bayona, J. V., Salvador García, C., Tormo Palop, N., and Gimeno Cardona, C. (2021). Validation and implementation of a commercial real-time PCR assay for direct detection of Candida auris from surveillance samples. Mycoses 64, 612-615. doi: 10.1111/myc.13250

Muthu, M., Chun, S., Wu, H. F., Duncan, M. W., and Gopal, J. (2018). The ongoing evolution of laser desorption/ionization mass spectrometry: Some observations on current trends and future directions. J. Mass Spectr. 53, 525-540. doi: $10.1002 / \mathrm{jms} .4083$
Mylonakis, E., Clancy, C. J., Ostrosky-Zeichner, L., Garey, K. W., Alangaden, G. J., Vazquez, J. A., et al. (2015). T2 magnetic resonance assay for the rapid diagnosis of candidemia in whole blood: a clinical trial. Clin. Infect. Dis. 60, 892-899. doi: 10.1093/cid/ciu959

Neely, L. A., Audeh, M., Phung, N. A., Min, M., Suchocki, A., Plourde, D., et al. (2013). T2 magnetic resonance enables nanoparticle-mediated rapid detection of candidemia in whole blood. Sci. Transl. Med. 5:182ra54. doi: 10.1126/ scitranslmed. 3005377

NIHR Global Health Research Unit on Genomic Surveillance of AMR (2020). Whole-genome sequencing as part of national and international surveillance programmes for antimicrobial resistance: a roadmap. BMJ Global Health 5:e002244. doi: 10.1136/bmjgh-2019-002244

O’Brien, B., Chaturvedi, S., and Chaturvedi, V. (2020). In vitro evaluation of antifungal drug combinations against multidrug-resistant Candida auris isolates from New York outbreak. Antimicrob. Agents Chemother. 64, e2195e2119. doi: 10.1128/AAC.02195-19

Ostrowsky, B., Greenko, J., Adams, E., Quinn, M., O’Brien, B., Chaturvedi, V., et al. (2020). Candida auris Isolates Resistant to Three Classes of Antifungal Medications - New York, 2019. MMWR Morb. Mort. Weekly Rep. 69, 6-9. doi: 10.15585/mmwr.mm6901a2

Pacilli, M., Kerins, J. L., Clegg, W. J., Walblay, K. A., Adil, H., Kemble, S. K., et al. (2020). Regional emergence of Candida auris in Chicago and lessons learned from intensive follow-up at 1 ventilator-capable skilled nursing facility. Clin. Infect. Dis. 71, e718-e725. doi: 10.1093/cid/ciaa435

Pla, L., Santiago-Felipe, S., Tormo-Mas, M. A., Ruiz-Gaitan, A., Peman, J., Valentin, E., et al. (2021). Oligonucleotide-capped nanoporous anodic alumina biosensor as diagnostic tool for rapid and accurate detection of Candida auris in clinical samples. Emerg. Microbes Infect. 10, 407-415. doi: 10.1080/22221751.2020. 1870411

Polinski, M., Hamilton, D. B., Nowak, B., and Bridle, A. (2013). SYBR, TaqMan, or both: highly sensitive, non-invasive detection of Cardicola blood fluke species in Southern Bluefin Tuna (Thunnus maccoyii). Mol. Biochem. Parasitol. 191, 7-15. doi: 10.1016/j.molbiopara.2013.07.002

Prakash, A., Sharma, C., Singh, A., Kumar Singh, P., Kumar, A., and Hagen, F. (2016). Evidence of genotypic diversity among Candida auris isolates by multilocus sequence typing, matrix-assisted laser desorption ionization timeof-flight mass spectrometry and amplified fragment length polymorphism. Clin. Microbiol. Infect. 2016:22. doi: 10.1016/j.cmi.2015.10.022

Qian, J., Cutler, J. E., Cole, R. B., and Cai, Y. (2008). MALDI-TOF mass signatures for differentiation of yeast species, strain grouping and monitoring of morphogenesis markers. Anal. Bioanal. Chem. 392, 439-449. doi: 10.1007/ s00216-008-2288-1

Ruiz Gaitan, A. C., Moret, A., Lopez Hontangas, J. L., Molina, J. M., Aleixandre Lopez, A. I., Cabezas, A. H., et al. (2017). Nosocomial fungemia by Candida auris: First four reported cases in continental Europe. Rev. Iberoam. Micol. 34, 23-27. doi: 10.1016/j.riam.2016.11.002

Ruiz-Gaitan, A. C., Fernandez-Pereira, J., Valentin, E., Tormo-Mas, M. A., Eraso, E., Peman, J., et al. (2018). Molecular identification of Candida auris by PCR amplification of species-specific GPI protein-encoding genes. Int. J. Med. Microbiol. 308, 812-818. doi: 10.1016/j.ijmm.2018.06.014

Sarma, S., Kumar, N., Sharma, S., Govil, D., Ali, T., Mehta, Y., et al. (2013). Candidemia caused by amphotericin B and fluconazole resistant Candida auris. Indian J. Med. Microbiol. 31, 90-91. doi: 10.4103/0255-0857.108746

Satoh, K., Makimura, K., Hasumi, Y., Nishiyama, Y., Uchida, K., and Yamaguchi, H. (2009). Candida auris sp. nov., a novel ascomycetous yeast isolated from the external ear canal of an inpatient in a Japanese hospital. Microbiol. Immunol. 53, 41-44. doi: 10.1111/j.1348-0421.2008.00083.x

Sattler, J., Noster, J., Brunke, A., Plum, G., Wiegel, P., Kurzai, O., et al. (2021). Comparison of Two Commercially Available qPCR Kits for the Detection of Candida auris. J. Fungi. 7:154. doi: 10.3390/jof7020154

Sexton, D. J., Bentz, M. L., Welsh, R. M., Derado, G., Furin, W., Rose, L. J., et al. (2021). Positive correlation between Candida auris skin-colonization burden and environmental contamination at a ventilator-capable skilled nursing facility in Chicago. Clin. Infect. Dis. 2021:327. doi: 10.1093/cid/ciab327

Sexton, D. J., Kordalewska, M., Bentz, M. L., Welsh, R. M., Perlin, D. S., and Litvintseva, A. P. (2018b). Direct detection of emergent fungal pathogen Candida auris in clinical skin swabs by SYBR Green-based quantitative PCR assay. J. Clin. Microbiol. 56, e1318-e1337. doi: 10.1128/JCM.01337-18 
Sexton, D. J., Bentz, M. L., Welsh, R. M., and Litvintseva, A. P. (2018a). Evaluation of a new T2 Magnetic Resonance assay for rapid detection of emergent fungal pathogen Candida auris on clinical skin swab samples. Mycoses 61, 786-790. doi: $10.1111 /$ myc. 12817

Sharp, A., Borman, A. M., Perera, N., Randle, M., Braham, S., Taori, S., et al. (2018). Assessing routine diagnostic methods for detecting Candida auris in England. J. Infect. 77, 448-454. doi: 10.1016/j.jinf.2018.07.012

Snayd, M., Dias, F., Ryan, R. W., Clout, D., and Banach, D. B. (2018). Misidentification of Candida auris by RapID Yeast Plus, a Commercial, Biochemical Enzyme-Based Manual Rapid Identification System. J. Clin. Microbiol. 56, e80-e18. doi: 10.1128/JCM.00080-18

Sugita, T., Takashima, M., Poonwan, N., and Mekha, N. (2006). Candida pseudohaemulonii Sp. Nov., an amphotericin B-and azole-resistant yeast species, isolated from the blood of a patient from Thailand. Microbiol. Immunol. 50, 469-473. doi: 10.1111/j.1348-0421.2006.tb03816.x

Sullivan, D. J., Westerneng, T. J., Haynes, K. A., Bennett, D. E., and Coleman, D. C. (1995). Candida dubliniensis sp. nov.: phenotypic and molecular characterization of a novel species associated with oral candidosis in HIVinfected individuals. Microbiology 141(Pt 7), 1507-1521. doi: 10.1099/ 13500872-141-7-1507

Tan, Y. E., Teo, J. Q., Rahman, N. B. A., Ng, O. T., Kalisvar, M., Tan, A. L., et al. (2019). Candida auris in Singapore: Genomic epidemiology, antifungal drug resistance, and identification using the updated 8.01 VITEK $\left({ }^{\circledR}\right) 2$ system. Int. J. Antimicrob. Agents 54, 709-715. doi: 10.1016/j.ijantimicag.2019.09.016

Theill, L., Dudiuk, C., Morales-Lopez, S., Berrio, I., Rodriguez, J. Y., Marin, A., et al. (2018). Single-tube classical PCR for Candida auris and Candida haemulonii identification. Rev. Iberoam Micol. 35, 110-112. doi: 10.1016/j.riam.2018.01. 003

Theodoropoulos, N. M., Bolstorff, B., Bozorgzadeh, A., Brandeburg, C., Cumming, M., Daly, J. S., et al. (2020). Candida auris outbreak involving liver transplant recipients in a surgical intensive care unit. Am. J. Transplant. 20, 3673-3679. doi: 10.1111/ajt.16144

Tian, S., Bing, J., Chu, Y., Chen, J., Cheng, S., Wang, Q., et al. (2021). Genomic epidemiology of Candida auris in a general hospital in Shenyang, China: a three-year surveillance study. Emerg. Microbes Infect. 10, 1088-1096. doi: 10. 1080/22221751.2021.1934557

Tsang, C. C., Chan, J. F., Ip, P. P., Ngan, A. H., Chen, J. H., Lau, S. K., et al. (2014). Subcutaneous phaeohyphomycotic nodule due to Phialemoniopsis hongkongensis sp. nov. J. Clin. Microbiol. 52, 3280-3289. doi: 10.1128/JCM. 01592-14

Tsay, S., Kallen, A., Jackson, B. R., Chiller, T. M., and Vallabhaneni, S. (2018). Approach to the Investigation and Management of Patients With Candida auris, an Emerging Multidrug-Resistant Yeast. Clin. Infect. Dis. 66, 306-311. doi: $10.1093 / \mathrm{cid} / \mathrm{cix} 744$

van Belkum, A., Welker, M., Pincus, D., Charrier, J. P., and Girard, V. (2017). Matrix-Assisted Laser Desorption Ionization Time-of-Flight Mass Spectrometry in Clinical Microbiology: What Are the Current Issues? Ann. Lab. Med. 37, 475-483. doi: 10.3343/alm.2017.37.6.475

Van Poucke, M., Van Zeveren, A., and Peelman, L. J. (2012). [Letter to the editor] Combined FAM-labeled TaqMan probe detection and SYBR green I melting curve analysis in multiprobe qPCR genotyping assays. Biotechniques 52, 81-86. doi: 10.2144/000113808

Vatanshenassan, M., Boekhout, T., Meis, J. F., Berman, J., Chowdhary, A., BenAmi, R., et al. (2019). Candida auris Identification and Rapid Antifungal Susceptibility Testing Against Echinocandins by MALDI-TOF MS. Front. Cell. Infect. Microbiol. 9:20. doi: 10.3389/fcimb.2019.00020

Walchak, R. C., Buckwalter, S. P., Zinsmaster, N. M., Henn, K. M., Johnson, K. M., Koelsch, J. M., et al. (2020). Candida auris Direct Detection from Surveillance Swabs, Blood, and Urine Using a Laboratory-Developed PCR Method. J. Fungi. 6:224. doi: 10.3390/jof6040224
Wang, T. Z., White, K. N., Scarr, J. V., Simon, M. S., and Calfee, D. P. (2020). Preparing your healthcare facility for the new fungus among us: An infection preventionist's guide to Candida auris. Am. J. Infect. Control. 48, 825-827. doi: 10.1016/j.ajic.2020.01.021

Weis, C. V., Jutzeler, C. R., and Borgwardt, K. (2020). Machine learning for microbial identification and antimicrobial susceptibility testing on MALDITOF mass spectra: a systematic review. Clin. Microbiol. Infect. 26, 1310-1317. doi: 10.1016/j.cmi.2020.03.014

Welsh, R. M., Bentz, M. L., Shams, A., Houston, H., Lyons, A., Rose, L. J., et al. (2017). Survival, Persistence, and Isolation of the Emerging MultidrugResistant Pathogenic Yeast Candida auris on a Plastic Health Care Surface. J. Clin. Microbiol. 55, 2996-3005. doi: 10.1128/JCM.00921-17

White, T. J., Bruns, T., Lee, S., and Taylor, J. (1990). "Amplification and direct sequencing of fungal ribosomal RNA genes for phylogenetics, diagnostics and forensics," in PCR Protocols:A guide to methods and applications, eds M. A. Innis, D. H. Gelfand, J. J. Sninsky, and T. J. White (San Diego: Academic Press). doi: 10.1016/B978-0-12-372180-8.50042-1

Wittwer, C. T., Herrmann, M. G., Moss, A. A., and Rasmussen, R. P. (2013). Continuous fluorescence monitoring of rapid cycle DNA amplification. 1997. Biotechniques 54, 314-320. doi: 10.2144/000114043

Won, E. J., Shin, J. H., Kim, M.-N., Choi, M. J., Joo, M. Y., Kee, S. J., et al. (2014). Evaluation of the BD Phoenix system for identification of a wide spectrum of clinically important yeast species: a comparison with Vitek 2-YST. Diagnost. Microbiol. Infect. Dis. 79, 477-480. doi: 10.1016/j.diagmicrobio.2014. 05.011

Yamamoto, M., Alshahni, M. M., Tamura, T., Satoh, K., Iguchi, S., Kikuchi, K., et al. (2018). Rapid Detection of Candida auris Based on Loop-Mediated Isothermal Amplification (LAMP). J. Clin. Microbiol. 56, e518-e591. doi: 10.1128/JCM. 00591-18

Yi, Q., Xiao, M., Fan, X., Zhang, G., Yang, Y., Zhang, J. J., et al. (2021). Evaluation of Autof MS 1000 and Vitek MS MALDI-TOF MS System in Identification of Closely-Related Yeasts Causing Invasive Fungal Diseases. Front. Cell Infect. Microbiol. 11:628828. doi: 10.3389/fcimb.2021.628828

Zhang, S. X., Carroll, K. C., Lewis, S., Totten, M., Mead, P., Samuel, L., et al. (2020). Multicenter Evaluation of a PCR-Based Digital Microfluidics and Electrochemical Detection System for the Rapid Identification of 15 Fungal Pathogens Directly from Positive Blood Cultures. J. Clin. Microbiol. 2020:58. doi: 10.1128/JCM.02096-19

Zhu, Y., O’Brien, B., Leach, L., Clarke, A., Bates, M., Adams, E., et al. (2020). Laboratory analysis of an outbreak of Candida auris in New York from 2016 to 2018: Impact and lessons learned. J. Clin. Microb. 58, e1503-e1519. doi: 10.1128/JCM.01503-19

Conflict of Interest: The authors declare that the research was conducted in the absence of any commercial or financial relationships that could be construed as a potential conflict of interest.

Publisher's Note: All claims expressed in this article are solely those of the authors and do not necessarily represent those of their affiliated organizations, or those of the publisher, the editors and the reviewers. Any product that may be evaluated in this article, or claim that may be made by its manufacturer, is not guaranteed or endorsed by the publisher.

Copyright (c) 2021 Dennis, Chaturvedi and Chaturvedi. This is an open-access article distributed under the terms of the Creative Commons Attribution License (CC BY). The use, distribution or reproduction in other forums is permitted, provided the original author(s) and the copyright owner(s) are credited and that the original publication in this journal is cited, in accordance with accepted academic practice. No use, distribution or reproduction is permitted which does not comply with these terms. 